\title{
ACTION OF PREGNANT MARE SERUM ON THE PRODUCTION OF TESTOSTERONE IN VIVO AND IN VITRO
}

\author{
KRISTEN B. EIK-NES AND PETER F. HALL \\ Department of Biological Chemistry, University of Utah College of Medicine, \\ Salt Lake City, and Department of Physiology, University of Pittsburgh, \\ Pittsburgh, Pa., U.S.A.
}

(Received 17th August 1964)

\begin{abstract}
Summary. Pregnant mare serum (PMS) increased the secretion of testosterone and the incorporation of acetate- $1-{ }^{14} \mathrm{C}$ into testosterone${ }^{14} \mathrm{C}$ when administered intravenously to anaesthetized dogs, whether the PMS was given as a single rapid injection or by continuous infusion during a period of $60 \mathrm{~min}$. When PMS was added to slices of rabbit testis in vitro, it increased both the incorporation of acetate- $1-{ }^{14} \mathrm{C}$ into testosterone${ }^{14} \mathrm{C}$ and the synthesis of testosterone as shown by measurements of radioactivity and mass of testosterone $-{ }^{14} \mathrm{C}$. It is therefore concluded that PMS is capable of increasing the biosynthesis of testosterone by testicular tissue and that the response of the testis to PMS is qualitatively the same as that to interstitial cell-stimulating hormone.
\end{abstract}

\section{INTRODUCTION}

At least three gonadotrophic hormones, namely human chorionic gonadotrophin (HCG) ovine interstitial cell-stimulating hormone (ICSH) and ovine follicle-stimulating hormone (FSH) are known to stimulate the production of testosterone by the canine testis in vivo (Brinck-Johnsen \& Eik-Nes, 1957; Eik-Nes, 1962) and to increase the incorporation of acetate-1 ${ }^{14} \mathrm{C}$ into testosterone-14 $\mathrm{C}$ by slices of rabbit testis in vitro (Brady, 1951; Hall \& Eik-Nes, 1962; Gower \& Haslewood, 1961). These actions are thought to be the outcome of a direct effect on the interstitial cells of the testis, which appears to result from an inherent property of HCG and ICSH (Evans \& Simpson, 1950), while in the case of FSH there is at present insufficient evidence to exclude the possibility of contamination with traces of ICSH (Eik-Nes, 1962; Hall \& Eik-Nes, 1962).

Less is known about the effect a fourth gonadotrophin, pregnant mare serum (PMS), has on steroid production by the testis. PMS appears to show both FSH-like activity and ICSH-like activity with greater emphasis on the former (Evans \& Simpson, 1950). The only report of the action of PMS upon the production of testosterone by the testis concerns a single observation by Lindner in a "poorly developed 3 month old Fresian calf" where the administration of PMS resulted in an increased secretion of testosterone (Lindner, 1961). 
It thus appeared to be important to establish if PMS could stimulate the production of testosterone in experiments in vivo as well as in vitro.

Measurement of testosterone in spermatic vein blood of the dog has proved a satisfactory method of studying gonadotrophic stimulation of the testis in vivo (Eik-Nes, 1962), while measurement of the incorporation of acetate-1-14 $\mathrm{C}$ into testosterone by slices of rabbit testis has provided a suitable system for the examination of gonadotrophic stimulation in vitro (Brady, 1951; Hall \& Eik-Nes, 1962). These two species of animal were accordingly used in the present studies.

\section{MATERIALS AND METHODS}

\section{Experiments in vivo}

The methods of continuous infusion via the spermatic artery at a constant rate together with simultaneous collection of spermatic venous blood and measurement of spermatic venous blood flow have been described in detail elsewhere (Brinck-Johnsen \& Eik-Nes, 1957; Eik-Nes, 1962). Pregnant mare serum was either injected rapidly during a period of $10 \mathrm{sec}$ or infused slowly during a period of $60 \mathrm{~min}$. Testosterone and testosterone-14 $\mathrm{C}$ were measured in spermatic venous blood by extraction of plasma, chromatographic isolation of testosterone followed by ultraviolet spectrometry and liquid scintillation spectrometry respectively as reported elsewhere (Eik-Nes, 1962).

In order to study the incorporation of acetate- $1-{ }^{14} \mathrm{C}$ into testosterone- ${ }^{14} \mathrm{C}$ by canine testes in vivo, it is necessary to prepare dogs by pretreatment with HCG as demonstrated previously (Mason \& Samuels, 1961). In the experiment to be reported one dog was given PMS (5000 i.u.) intramuscularly daily for 10 days.

\section{Experiments in vitro}

Slices of rabbit testis (500 mg wet wt/flask) were prepared as previously described and incubated with sodium acetate-1-14 $\mathrm{C}$ (135 $\mu \mathrm{g} ; 30 \mu \mathrm{c} /$ flask) in Krebs-Ringer bicarbonate buffer according to the details given by Hall \& Eik-Nes (1962).

Following incubation the tissue was homogenized in the incubation medium, an aliquot removed for measurement of protein content, $100 \mathrm{\mu g}$ testosterone added and the mixture extracted as described (Hall \& Eik-Nes, 1962). The dry extracts were applied to paper in the system ligroin/propylene glycol for $24 \mathrm{hr}$ (Brady, 1951). The added testosterone was located by means of an ultraviolet scanner (Haines \& Drake, 1950). The area of the chromatogram occupied by testosterone was cut out and counted by liquid scintillation spectrometry (Hall, Sozer \& Eik-Nes, 1964). Evidence for the identity and radiochemical purity of this material as testosterone $-{ }^{14} \mathrm{C}$ and the methods used to obtain this evidence by reverse isotope dilution have been given elsewhere (Hall \& EikNes, 1962; Hall et al., 1964).

Since the production of testosterone by slices of testis in vitro was less than $0.1 \mu \mathrm{g} /$ flask (the minimal amount which could be measured accurately by the system of gas chromatography used here), it was necessary to pool extracts from four flasks in order to measure the mass of testosterone by means of gas chroma- 
tography. In one experiment the production of testosterone was determined by gas chromatography of pooled extracts from slices incubated with and without PMs. The methods used, including details of gas chromatography, are given elsewhere (Hall, Nishizawa \& Eik-Nes, 1963). Duplicate determinations of authentic testosterone in amounts of $0 \cdot 1$ to $5 \mu \mathrm{g}$ determined by this method fell within the limits $\pm 8 \%$.

When the action of PMS upon the rabbit testis in vivo was studied, the animal was anaesthetized with nembutal, one testis removed, sliced and incubated with sodium acetate-1-14 C. A single intravenous injection of PMS was administered to the animal and $1 \mathrm{hr}$ later the second testis removed and incubated under the same conditions (Hall \& Eik-Nes, 1962).

The details of the methods of counting by liquid scintillation spectrometry have been reported by Hall et al. (1964). Counting efficiency in the present experiments was 54 to $56 \%$ and the expression dpm refers to values corrected for this efficiency.

Recovery of testosterone and testosterone- ${ }^{14} \mathrm{C}$ from plasma by the methods used (Eik-Nes, 1962) was measured by adding known amounts of these substances to dog plasma and was found to vary between 80 to $85 \%$ in 103 experiments. When testosterone $-4-{ }^{14} \mathrm{C}$ was added to slices of rabbit testis and extracted by the present method (Hall \& Eik-Nes, 1962), recovery of testosterone ${ }^{14} \mathrm{C}$ was found to be between 76 and $84 \%$ in forty experiments. The data reported here have been corrected for these recoveries.

The protein content of slices of testis was measured by the method of FolinCiocalteu (Colowick \& Kaplan, 1957). The incorporation of ${ }^{14} \mathrm{C}$ into testosterone is expressed in the accompanying tables as $\mathrm{dpm} / 100 \mathrm{mg}$ of testicular protein. The protein content of $500 \mathrm{mg}$ of slices of testis was found to be between 26 and $32 \mathrm{mg}$. In the experiments in vitro slices of testis from one rabbit are compared only with slices from the same animal.

ICSH was weighed on a microbalance (Mettler) in $1 \mathrm{mg}$ lots and dissolved in buffer so that $0 \cdot 1 \mathrm{ml}$ of the solution contained $10 \mu \mathrm{g}$ ICSH. Pregnant mare serum was weighed on a semimicrobalance (Mettler); $10 \mathrm{mg}$ of Equinex (Ayerst preparation of pregnant mare serum) contained $430 \mathrm{i} . \mathrm{u}$. of PMS.

Sodium acetate- $1-14 \mathrm{C}$ was obtained from New England Nuclear Corporation and ICSH was provided by the Endocrine Study Section of the National Institutes of Health in the form of the preparation called NIH-LH-S-4. Pregnant mare serum was generously provided by Ayerst Laboratories Inc., New York, as Equinex (No. 490) and ACTH was a gift of The Upjohn Company.

Experiments in vivo

\section{RESULTS}

(1) Secretion of testosterone. Table 1 shows the results of experiments with five dogs in which the secretion of testosterone into the left spermatic vein was measured by collecting blood from this vessel during a period of $90 \mathrm{~min}$. After the first $30 \mathrm{~min}$ of collection, a rapid injection $(10 \mathrm{sec})$ of $\mathbf{P M S}$ was given intravenously. The secretion of testosterone by the left testis (expressed as $\mu \mathrm{g} / 30 \mathrm{~min}$ ) is shown for dogs receiving various doses of PMs. It is seen that 1 or 2 i.u. of 
PMS/kg body weight produced no demonstrable change in the level of testosterone in the spermatic vein blood but prevented the decrease in testosterone production usually seen in the anaesthetized dog in such experiments (Eik-Nes, 1962). Higher doses of PMS (10 to $150 \mathrm{i} . \mathrm{u} . / \mathrm{kg}$ body wt) greatly increased the rate of secretion of testosterone during the first $30 \mathrm{~min}$ after injection.

TABLE 1

LEVELS OF TESTOSTERONE IN SPERMATIC VEIN PLASMA BEFORE AND AFTER RAPID INTRAVENOUS ADMINISTRATION OF PMS VIA A FORELEG VEIN (FIVE DOGS)

\begin{tabular}{l|c|c|c|c}
\hline \multirow{2}{*}{ Dog } & & \multicolumn{3}{|c}{ Testosterone $(\mu \mathrm{g} / 30 \mathrm{~min})$} \\
\cline { 3 - 5 } & Total dose $($ i.u. $/ \mathrm{kg})$ & Before PMS & \multicolumn{2}{|c}{ Afler PMs } \\
\cline { 3 - 5 } & & $(0$ to $30 \mathrm{~min})$ & $(30$ to $60 \mathrm{~min})$ & $(60$ to $90 \mathrm{~min})$ \\
\hline PAK & 1 & 4 & 3 & 3 \\
PAL & 2 & 3 & 3 & 4 \\
PAM & 10 & 16 & 26 & 102 \\
PAN & 130 & 5 & 34 & 120 \\
PAO & 150 & 9 & 28 & 98 \\
\hline
\end{tabular}

The left spermatic vein of each dog was cannulated and blood collected throughout the $90 \mathrm{~min}$ of observation. The plasma was separately extracted in these samples, each representing a period of $30 \mathrm{~min}$ collection. The testosterone was determined in each sample as $\mu \mathrm{g} / 30 \mathrm{~min}$. After the first $30 \mathrm{~min}$ of collection a rapid injection (10 sec) of PMs, dissolved in $0.9 \%$ sodium chloride, was administered via a vein of the left foreleg.

TABLE 2

LEVELS OF TESTOSTERONE IN SPERMATIC VEIN PLASMA BEFORE AND DURING CONTINUOUS INTRAVENOUS ADMINISTRATION OF PMS VIA A FORELEG VEIN (FOUR DOGS)

\begin{tabular}{l|c|c|c|c}
\hline \multirow{2}{*}{ Dog } & & \multicolumn{3}{|c}{ Testosterone $(\mathrm{ug} / 30 \mathrm{~min})$} \\
\cline { 3 - 5 } & Total dose $(\mathrm{i} . u . / \mathrm{kg})$ & Before PMs & \multicolumn{2}{|c}{ During PMs infusion } \\
\cline { 2 - 5 } & & $(0$ to $30 \mathrm{~min})$ & $(30$ to $60 \mathrm{~min})$ & $(60$ to $90 \mathrm{~min})$ \\
\hline PAG & 175 & 11 & 12 & 32 \\
PAA & 170 & 34 & 36 & 200 \\
PAS & 170 & 19 & 29 & 93 \\
PAQ & 170 & 4 & 14 & 58 \\
\hline
\end{tabular}

The methods used in these experiments differ from those reported in Table 1 only in the mode of administration of PMS, which in the present experiments was by continuous infusion during the last $60 \mathrm{~min}$ of each experiment.

The response to infusion of PMS via a vein of the foreleg at a constant rate for $60 \mathrm{~min}$ is shown in Table 2. Again the production of testosterone in all four dogs was increased.

(2) Incorporation of acetate-1-14C into testosterone. In one dog pretreated with HCG as described under Materials and Methods, sodium acetate- $1-14 \mathrm{C}$ was infused at a constant rate via both spermatic arteries for $90 \mathrm{~min}$ and blood was 
collected from each spermatic vein during this period. At the end of the first 30 min of this infusion of acetate-1-14 C, PMs ( $300 \mathrm{i} . u$. $/ \mathrm{kg}$ body wt) was added to the infusion of the right spermatic artery and ACTH (25 i.u.) to that of the left spermatic artery. The samples of blood collected from the right and left spermatic veins were separately extracted, testosterone ${ }^{14} \mathrm{C}$ isolated and measured both as mass and rádioactivity. It will be seen from Text-fig. 1 that PMS caused a marked increase in the incorporation of ${ }^{14} \mathrm{C}$ into testosterone while ACTH was

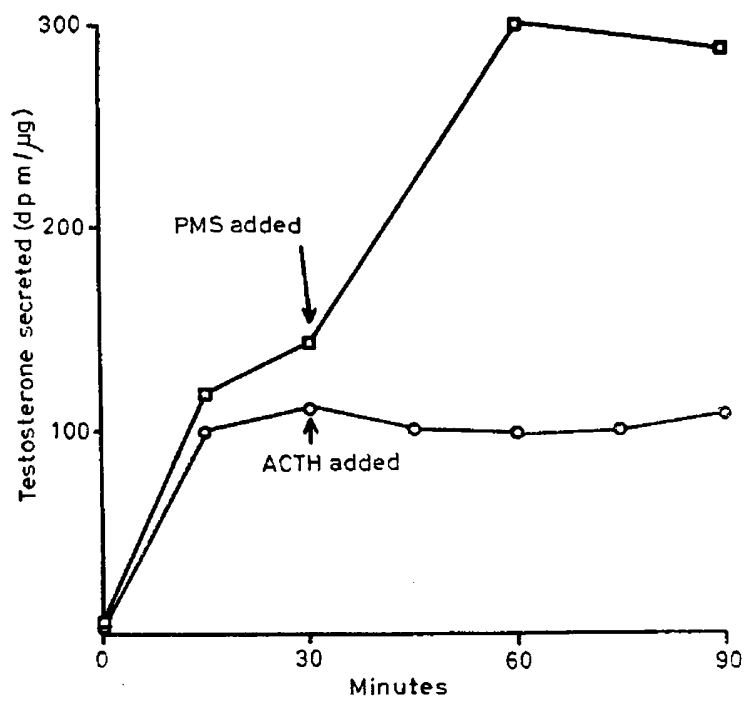

TEXT-FIG. 1. Specific activity of testosterone secreted by the testes of a $20 \mathrm{~kg} \mathrm{dog}$. This dog was given 5000 i.u. of PMs intramuscularly for ten consecutive days and the experiment was performed on the 11th day. Both spermatic arteries were cannulated and infusion with a solution of sodium acetate-1-14 $\mathrm{C}$ in normal saline $(36 \mathrm{ml})$ was commenced. During the next $90 \mathrm{~min} 60 \mu \mathrm{c}(360 \mu \mathrm{g})$ of acetate-1-14 $\mathrm{C}$ was infused via each spermatic artery. Thirty min after commencing the infusion, ACTH $(25 \mathrm{i} . u$. $/ \mathrm{kg}$ body wt) was added to the infusing fluid of the left testis $(O)$ and PMS (300 i.u. $/ \mathrm{kg}$ body wt) added to that of the right testis $(\square)$. Both testes were perfused with arterial blood at a constant rate of $3.9 \mathrm{ml} / \mathrm{min}$ throughout the experiment.

without demonstrable effect. It has been shown elsewhere (Eik-Nes, 1962) that ACTH does not influence the secretion of testosterone under the conditions of this experiment.

\section{Experiments in vitro}

Table 3 presents the results of three experiments in which slices of testis were incubated in vitro with acetate-1 $1{ }^{14} \mathrm{C}$ with and without the two gonadotrophic hormones ICSH and PMs. It will be seen that in flasks without either hormone, some incorporation of ${ }^{14} \mathrm{C}$ into testosterone is found and that $10 \mu \mathrm{g}$ of $\mathrm{ICSH}$ greatly increased this incorporation (Experiment 1, Table 3), thus confirming earlier findings (Hall \& Eik-Nes, 1962; Hall et al., 1963, 1964). When PMs was added to the medium, a considerable increase in incorporation of ${ }^{14} \mathrm{C}$ into testosterone was seen and 10 units of PMS appeared to produce a response approximately equal to half that produced by $10 \mu \mathrm{g}$ ICSH. Experiment 3 (Table 3 ) shows that PMS not only increased the incorporation of acetate- $1-{ }^{14} \mathrm{C}$ into 
testosterone but also increased the absolute amount of testosterone synthesized.

In each of three experiments ( 4 to 6 shown in Table 4 ) one rabbit was anaesthetized, the left testis removed, sliced and incubated with acetate-1-14 $\mathrm{C}$ as described under Table 4. After removal of the left testis a single intravenous injection of PMS (200 i.u./kg body weight) was administered and $1 \mathrm{hr}$ later the right testis was removed and incubated with acetate-1-14 $\mathrm{C}$ as before. It will be seen (Table 4) that a single intravenous injection of PMS greatly increased the incorporation of acetate- $1-{ }^{14} \mathrm{C}$ into testosterone by slices of testis in vitro.

TABLE 3

THE EFFEGT OF PMS AND OF ICSH UPON THE INCORPORATION OF ACETATE- $1-{ }^{14} \mathrm{C}$ INTO TESTOSTERONE- ${ }^{14} \mathrm{C}$ AND ON THE SYNTHESIS OF TESTOSTERONE BY SLICES OF RABBIT TESTIS

\begin{tabular}{|c|c|c|c|}
\hline \multirow[b]{2}{*}{ Experiment } & \multicolumn{2}{|c|}{ Gonadotrophin } & Testosterone ${ }^{-14} C$ \\
\hline & $\begin{array}{c}\text { ICSH } \\
(\mu g / \text { flask })\end{array}$ & $\begin{array}{c}\text { PMS } \\
\text { (i.u.|flask })\end{array}$ & (dpm/100 mg testicular protein) \\
\hline 1 & $\begin{array}{r}0 \\
10 \\
10 \\
0 \\
0 \\
0 \\
0 \\
0\end{array}$ & $\begin{array}{r}0 \\
0 \\
0 \\
100 \\
200 \\
200 \\
500 \\
500\end{array}$ & $\begin{array}{r}7,900 \\
92,200 \\
86,500 \\
58,700 \\
113,000 \\
101,000 \\
119,000 \\
126,000\end{array}$ \\
\hline 2 & $\begin{array}{r}0 \\
0 \\
10 \\
10 \\
0 \\
0 \\
0 \\
0\end{array}$ & $\begin{array}{r}0 \\
0 \\
0 \\
0 \\
10 \\
10 \\
20 \\
20\end{array}$ & $\begin{array}{r}1,500 \\
1,400 \\
18,700 \\
17,100 \\
9,400 \\
8,900 \\
21,800 \\
20,700\end{array}$ \\
\hline Experiment & \multicolumn{2}{|c|}{$\begin{array}{c}\text { PMS } \\
(i .2 u . \mid \text { flask })\end{array}$} & $\begin{array}{l}\text { Testosterone } \\
\quad(\mathrm{\mu g})\end{array}$ \\
\hline 3 & \multicolumn{2}{|c|}{$\begin{array}{r}0 \\
500\end{array}$} & $\begin{array}{r}<0.1 \\
1.3\end{array}$ \\
\hline
\end{tabular}

In Experiment 3, four flasks were incubated without PMS and four were incubated with PMS. Following incubation the contents of flasks without PMS were pooled and those with PMS were similarly pooled. Testosterone was measured by gas chromatography as described elsewhere (Hall et al., 1963).

\section{DISCUSSION}

Although it is generally believed that the gonadotrophic activity of PMS is predominantly like that of FsH (Evans \& Simpson, 1950), it is clear that the preparation used in these experiments was capable of increasing the production of testosterone by testis in vivo and in vitro in two species of animal. The present findings indicate considerable stimulation of interstitial cells by PMS and confirm the report by Lindner (1961) that this hormone stimulated the production of testosterone by a bull calf.

One or two i.u. of PMS $/ \mathrm{kg}$ body weight administered intravenously to a dog 
prevented the decline in the secretion of testosterone usually seen in the anaesthetized dog (Eik-Nes, 1962) (Table 1). These responses are comparable to those previously reported for 1 or 2 i.u. of HCG/kg body wt (Brinck-Johnsen \& Eik-Nes, 1957), suggesting that in the present system the two hormones are of approximately equal activity unit for unit. Also the time course of the response to PMS in vivo and the dose (expressed in i.u.) required to produce maximal stimulation of testosterone secretion are in general similar to those previously reported for HGG.

\section{TABLE 4}

THE EFFECT OF PMS ADMINISTERED INTRAVENOUSLY UPON THE RATE OF INCORPORATION OF ACETATE-1 ${ }^{14} \mathrm{C}$ INTO TESTOSTERONE- ${ }^{14} \mathrm{C}$ BY SLICES OF RABBIT TESTIS in vitro (EXPERIMENTS 4 TO 6 )

\begin{tabular}{c|c|c}
\hline \multirow{3}{*}{ Experiment } & \multicolumn{2}{|c}{ Testosterone-14C } \\
\cline { 2 - 3 } & \multicolumn{2}{|c}{$(d$ dpm/100 mg testicular protein $)$} \\
\hline 4 & Left testis (before PMs) & Right testis (after PMs) \\
\hline 5 & 6100 & 185,000 \\
& 6400 & 178,000 \\
& 6200 & 181,000 \\
\hline 6 & 4700 & 143,000 \\
& 4200 & 147,000 \\
& 4000 & 150,000 \\
\hline 5 & 5000 & 92,000 \\
& 4800 & 101,000 \\
& 4100 & 108,000 \\
\hline
\end{tabular}

Each rabbit was anaesthetized, the left testis removed, sliced and incubated with sodium acetate $-1-14 \mathrm{C}(30 \mu \mathrm{c}$, $135 \mu \mathrm{g})$, each testis being distributed equally between three flasks. Immediately after removing the left testis, a single intravenous injection of PMS ( $200 \mathrm{i} . \mathrm{u}$./ $\mathrm{kg}$ body wt) in normal saline was given intravenously. One hr later the right testis was removed, sliced and incubated as before.

The experiments in vitro show in the first place that Pus increases the production of testosterone by rabbit testis in a manner analagous to that previously reported for ICSH, i.e. these two gonadotrophic hormones share three actions on the testis:

(1) Both increase the incorporation of acetate-1-14 $\mathrm{C}$ into testosterone- ${ }^{14} \mathrm{C}$ by slices of testis when they are added to the tissue in vitro (Experiments 1 and 2 in Table 3 for PMs and the report of Hall \& Eik-Nes (1962) for Icsh).

(2) This response is accompanied by an increase in the amount of testosterone synthesized as determined by measurement of mass (Experiment 3 in Table 3 for PMS and the work of Hall, Nishizawa \& Eik-Nes (1963) for ICSH), and

(3) A single intravenous injection of both gonadotrophic hormones produces in vivo some change(s) which is (are) expressed in vitro by increased incorporation of acetate- $1{ }^{14} \mathrm{C}$ into testosterone by slices of testis above the level 
shown by the testis removed before stimulation (Experiments 4,5 and 6 in Table 4 for PMs and the data of Hall \& Eik-Nes (1962) for xcsh).

In the second place the experiments in vitro may indicate that the pituitary gland is not essential for the action of PMS upon the testis. Not only is PMS capable of producing marked stimulation of interstitial cells in vitro but the response of the testis resembles that shown for ICSH. Since no experiment in vitro was done in hypophysectomized animals, it is possible that the testicular slices used contained endogenous gonadotrophin. Thus our data do not exclude the possibility that the effect of PMS on testosterone production is augmented in the presence of the pituitary gonadotrophins.

A further point of similarity between the effect of ICSH, HCG and PMS upon the production of testosterone was revealed in the experiments in vivo. Not only was the production of testosterone from endogenous precursors increased by PMS ( $\mu$ g testosterone/30 min in Tables 1 and 2) but the proportionate incorporation of acetate- $1-{ }^{14} \mathrm{C}$ into testosterone was increased as shown by a rise in specific radioactivity ( $\mathrm{dpm}{ }^{14} \mathrm{C} / \mathrm{\mu g}$ testosterone in Text-fig. 1 ). The same changes have been observed following the administration of HCG and ICSH to dogs (Mason \& Samuels, 1961; Eik-Nes, 1962). Although these experiments clearly demonstrate that PMs is capable of direct stimulation of testicular tissue as measured by the production of testosterone, they do not serve to clarify the mechanism(s) by which this action is mediated nor do they help to answer the question of whether FSH is required for increased production of testosterone in the presence of ICSH.

The observation that ACTH was without effect upon the production of testosterone (Text-fig. 1) is entirely expected and serves as a reminder that in spite of numerous points of similarity between the mechanism(s) by which ACTH and gonadotrophic hormones increase the synthesis of steroids (Savard, Marsh \& Howell, 1963), the target organs show a high order of specificity in their responses to different trophic hormones (Eik-Nes, 1962; Savard et al., 1963).

\section{ACKNOWLEDGMENTS}

A brief report of some of the present data can be found in the Transactions of the Second Asia and Oceania Congress of Endocrinology, Symposium on Reproduction, Sydney, Australia, May 1963. These investigations were supported by research grants AM 06651-02 and AM 06459-02 from the National Institute of Arthritis and Metabolic Diseases, U.S. Public Health Service, Bethesda, Maryland, U.S.A.

\section{REFERENCES}

Albert, A. (1961) Sex and internal secretion, p. 337. Ed. W. G. Young and G. W. Corner. Williams \& Wilkins, Baltimore.

BRADY, R. O. (1951) Biosynthesis of radioactive testosterone in vitro. F. biol. Chem. 193, 145.

Brinck-Johnsen, T. \& Eik-Nes, K. (1957) Effect of human chorionic gonadotropin on the secretion of testosterone and 4-androstene-3,17-dione by the canine testis. Endocrinology, 61, 676.

Colowick, S. P. \& Kaplan, N. O. (1957) Methods in enzymology, Vol. III, p. 448. Academic Press, New York.

EIK-Nes, K. B. (1962) Secretion of testosterone in anesthetized dogs. Endocrinology, 71, 101.

Evans, H. M. \& Simpson, M. E. (1950) The hormones, p. 388. Ed. G. Pincus and K. V. Thimann. Academic Press, New York. 
Gower, D. B. \& Haslewood, G. A. D. (1961) Biosynthesis of androst-16-en-3 $\alpha$-ol from acetate by testicular slices. 7. Endocrin. 23, 253.

Haines, J. \& DRAKE, N. A. (1950) Fluorescence scanner for evaluation of papergrams of adrenal cortical hormones. Fed. Proc. 9, 180.

HALl, P. F. \& EIK-NEs, K. B. (1962) The action of gonadotropic hormones upon rabbit testis in vitro. Biochim. biophys. Acta, 63, 411 .

Hall, P. F., Nishizawa, E. E. \& EiK-Nes, K. B. (1963) The biosynthesis of testosterone by rabbit testis: Homogenate v slices. Proc. Soc. exp. Biol., N.Y. 114, 791.

Hall, P. F., Sozer, G. G. \& Eik-Nes, K. B. (1964) The role of dehydroepiandrosterone in the biosynthesis of testosterone in vivo and in vitro. Endocrinology, 74, 35 .

LindNER, H. R. (1961) Androgens and related compounds in the spermatic vein blood of domestic animals. I. Neutral steroids secreted by the bull testis. F. Endocrin. 23, 139.

Mason, N. R. \& Samuels, L. T. (1961) Incorporation of acetate-1-14C into testosterone and $3 \beta-$ hydroxysterols by the canine testis. Endocrinolog $y, 68,899$.

Savard, K., Marsh, J. M. \& Howell, D. S. (1963) Progesterone biosynthesis in luteal tissue: Role of nicotinamide adenine dinucleotide phosphate and NADP-linked dehydrogenases. Endocrinology, 73,554 . 